\title{
A designerly critique on enchantment
}

\author{
Philip R. Ross · C. J. Overbeeke · Stephan A. G. Wensveen · \\ Caroline M. Hummels
}

Received: 19 December 2005/ Accepted: 4 September 2006/Published online: 17 March 2007

(C) Springer-Verlag London Limited 2007

\begin{abstract}
To develop the concept of user experience in $\mathrm{HCI}, \mathrm{McC}$ arthy et al. introduce the notion of enchantment in interaction design. They describe five sensibilities that support exploration and evaluation in design for enchantment. In this paper, we discuss design for enchantment in light of our approach to design for interaction, called design for meaningful mediation. Based on our experiences from case studies, we argue that 'considering the whole person with feelings, desires and anxieties', one of the sensibilities McCarthy et al. formulate, influences the desirability and realisation of the other four sensibilities. By way of case studies, we show how we explored the link between 'the whole person' and desired interaction experience in a designerly way. We place enchantment in a context of other interaction experiences and demonstrate possible design techniques relevant to design for interaction experiences, including enchantment.
\end{abstract}

P. R. Ross $(\bowtie) \cdot$ C. J. Overbeeke · S. A. G. Wensveen

Department of Industrial Design, Technische Universiteit Eindhoven, Den Dolech 2, P.O. Box 513, 5600 MB Eindhoven,

The Netherlands

e-mail: p.r.ross@tue.nl

URL: http://www.idemployee.id.tue.nl/p.r.ross/

C. J. Overbeeke

School of Design, Carnegie Mellon University, Pittsburgh

PA 15213, USA

C. M. Hummels

Industrial Design Engineering, Delft University of Technology,

Landbergstraat 15, 2628 CE Delft, The Netherlands

\section{Introduction}

\subsection{Regarding enchantment}

Bennet [1] defines the concept of enchantment as 'the experience of being caught up and carried away, in which, although we are disoriented, perception and attention are heightened.' McCarthy et al. [2] argue that this concept of enchantment could both serve as a perspective to reflect on interactive products and systems and as a catalyst for exploring new interaction designs. In this view, depth of an interactive product or system is central to a lasting experience of enchantment. McCarthy et al. characterize depth through five sensibilities that could help in devising and evaluating interactive designs in terms of enchantment. These five sensibilities are described as follows:

1. 'the specific sensuousness of each particular thing',

2. 'the whole person with desires, feelings, and anxieties',

3. 'a sense of being-in-play',

4. 'paradox, openness, and ambiguity' and

5. 'the transformational character of experience'.

Using enchantment to evaluate and explore design for experience opens up aspects of interaction design that normally remain underdeveloped in HCI, like cultural aspects of interaction. According to McCarthy et al., the downside of placing enchantment central to interaction design is that it is prone to result in detached passive experience.

Our own approach to design for interaction, called design for meaningful mediation, touches upon aspects of design related to design for enchantment. Our research allows us to critically review the sensibilities as outlined by McCarthy et al. and expand on the notion with insights 
from design activity. We acknowledge the value of viewing experiences with interactive technology in terms of enchantment, and see the need for the sensibilities treated earlier. Our main point of critique is however, that operating from these five sensibilities may well lead to nonenchanting experiences or 'detached passive experiences' that McCarthy et al. warn against. In our view sensibility 2, which is directed solely at the person level, has implications for the desirability and the realisation of sensibility 1 , 3,4 and 5, which are directed at interaction between person and object.

Our research also allows us to place enchantment in the context of other desired interaction experiences. In this paper, we use three design case studies we conducted in our 'design for meaningful mediation' research to explain how we would like to nuance McCarthy et al.'s work on enchantment and place it in context. Furthermore, these case studies offer techniques to bring the interaction experience theory treated in this paper into design practice. Before we continue with the case studies, we briefly outline the underlying philosophy behind design for meaningful mediation.

\subsection{Design for meaningful mediation}

In our research we view devices in terms of their mediating role in people's everyday lives. Devices help shape people as actors in the world. This is what Verbeek [3] refers to as the mediating role of technology in the human-world relationship. Wearing a mobile audio device like a Discman or iPod changes the way we experience the world and also changes the way we interact with people in close vicinity. When devices mediate our involvement of the world, they amplify specific ways of involvement with reality and reduce others. More specifically, devices invite us to be involved with aspects of reality and inhibit our involvement with other aspects. On the one hand, a Discman invites us to enjoy music everywhere we go (invitation), but on the other hand it creates a social barrier that hinders interaction with people in the vicinity (inhibition). Verbeek discerns two dimensions of involvement mediated by technology, i.e., 'physical engagement' and 'meaningful engagement'. Physical engagement with the world is about exerting oneself physically and capitalizing on physical skills. A fireplace for example, asking its owner to go out and chop wood for heating, invites more physical engagement with the world than a central heating system, operated by turning a thermostat. The other dimension of engagement, 'meaningful engagement', connects to people's moral beliefs and aspirations in life. Being meaningfully engaged with the world is being involved in an activity one considers intrinsically valuable. This means the activity is valuable as an end in itself instead of as a means to another end. A musical instrument, for example, invites meaningful engagement in multiple ways. It invites a person to self-express emotionally through music, it invites valuable communication with an audience and fellow musicians and it invites the musician to improve his motor skills on the instrument.

In contrast to both types of technologically mediated involvement, physical and meaningful, a device could reduce our involvement with the world through inviting consumptive practice. In this case, interaction with a device results in passive consumption of a commodity. An environment with many devices inviting consumptive practice inhibits meaningful engagement with the world, since consumptive practice supplants the space for meaningful engagement. The dishwasher in a family home provides an example, as Vorstenbosch [4] describes. Although the dishwasher relieves us from a daily, time consuming task, it also takes away a context for useful social interactions in the home that exists thanks to the informal atmosphere of doing the dishes together. A possibly meaningfully engaging activity is replaced by consuming the commodity of machine-washed dishes. Of course, for many families the dishwasher is a welcome helping hand that frees space for other, possibly meaningful activities by relieving them from the dishwashing task. But the question remains: which devices would invite meaningful social interactions instead? It seems that if we regard casual social interactions in a family home as valuable, many devices in home environments invite consumptive practice rather than meaningful engagement. See for example the social effect within the family of personal television sets in the home. We do not contend that such a technology is inherently a bad thing, just that it seems to invite consumptive practice in many cases that may not be beneficial to family life at home.

More, new technologies continuously emerge in the everyday living environment, giving designers exciting new possibilities to enrich people's lives. The vision of Ambient Intelligence promises networks of context aware, personalised, adaptive and anticipatory devices, integrated in our daily life [5]. As technology increasingly 'weaves into the fabric of everyday life', an ever greater part of our involvement with reality will be mediated by technology. We think that the exciting new possibilities these technological developments create for design cannot be separated from the responsibility for design to consider their mediation in the lives of people: to what extent will a product invite or inhibit meaningful engagement with the world? In this paper, we research mediation from a design perspective: how can we design new home products and systems for meaningful mediation? In the next section, the three case studies mentioned earlier are outlined, along with conclusions related to design for enchantment. 


\section{Three case studies}

First of all we treat 'Coppia Espressiva', an installation consisting of two musical devices. Many consider selfexpression through making music an intrinsically valuable and enchanting activity. How can interactive technology mediate such meaningful engagement? We investigated how two different approaches to interaction design, differing regarding sensibilities 1, 3, 4 and 5 (sensuousness, being-in-play, openness, transformational character) influence people's ability to self-express through music. We found that the participants in this case study split into two groups: those that liked openness, being-in-play and those that clearly did not. This indicated to us the significance of considering 'the whole person with desires feelings and anxieties' (sensibility 2) before determining if and how to apply the other sensibilities.

In the second case study, the workshop 'Ethics and Aesthetics in Interaction', we made a first attempt to include the 'whole person' in design for mediation, by linking different ways of ethical thinking to design for aesthetics of interaction. This workshop explored how different ways of ethical thinking can be incorporated in design of interactive products, and explored how this influences the potential for evoking meaningful engagement. We learned that ethics gave direction in determining which of sensibilities $1,3,4$ and 5 to realise and how to realise them in design of aesthetics of interaction.

In the third project described in this paper, 'Incorporating Human Values in Interaction' we attempted to find a framework of possible interaction experiences, including enchantment, linked to the different desires, feelings and anxieties people may have. We used human value theory from social psychology as a framework and explored how intelligent products could incorporate human values in interaction. In a pilot study, dancers acted out intelligent lights, aiming to incorporate a specific human value in interaction. This study pointed towards a way to see enchantment in the context of other desired interaction experiences. Furthermore, it offered possible design techniques that are applicable to design for enchanting interaction experience in the context of intelligent products.

\subsection{Coppia Espressiva}

The first project we describe is Coppia Espressiva, a project conducted at Delft University of Technology [6]. We investigated how to design for meaningful mediation, focusing on the activity of emotional self-expression through music. We selected this specific activity, since it is commonly considered intrinsically valuable and enchanting. We describe the two different design approaches, 'semantic' and 'direct', and the resulting devices Poco and
Moto. We summarise our main findings in terms of the influence of the design approach on people's ability to selfexpress emotionally and what these findings tell us about design for enchantment.

\subsubsection{Two design approaches}

The semantic approach relies on the basic idea that we use our knowledge and experience to interpret the symbols and signs of products [7]. Products use metaphors in which the functionality and expression of the new product is compared to an existing concept or product that the user is familiar with. Emoticons in instant messenger applications are examples of emotionally expressive semantic interaction in the domain of on screen interaction.

The direct approach is action based. It is inspired by Gibson's perception theory, which states that meaning is created through the interaction between person and the world [8]. Perception is action, which reminds us of the phenomenological concept of technological mediation outlined in the introduction. It seems plausible that a device designed from the direct approach, which allows a person to actively create his own expression would allow more emotional involvement. This approach would thus more likely allow a person to be meaningfully engaged with the activity of emotional self-expression and evoke an enchanting experience than a device that offers pre-created expressions.

\subsubsection{Poco: the semantic approach}

The first device we treat is Poco, which incorporates emotional expression in static objects. Poco consists of a plywood body, a rotating stage, a brass horn and three sets of expressive physical objects. See Fig. 1.

Each set of expressive objects represents a layer of music; a set of 10 objects represents the rhythms, a set of 10 objects represents the two-chord harmonics and a set of 5 objects represents the sampled sounds of nature. All objects are designed to reflect their musical emotional expression in their appearance. Musical expressions are made by combining one object from each set, rhythm, chord and sample of nature, on the rotating platform.

\subsubsection{Moto: the direct approach}

The device designed from the direct approach, capitalizing on emotional expression of physical actions, is called Moto. Moto consists of a water reservoir, a body of plywood and a set of eight tools. See Fig. 2.

Music is created by moving one or two tools through the water. The feel of moving the tools in the water determines 
Fig. 1 Poco, designed from the semantic approach, incorporates emotional expression in objects. Left to the horn are the harmonic objects, right of it the rhythm objects and in front of it objects representing samples of nature. The right picture shows a rhythm object and a harmonic object on the rotating stage
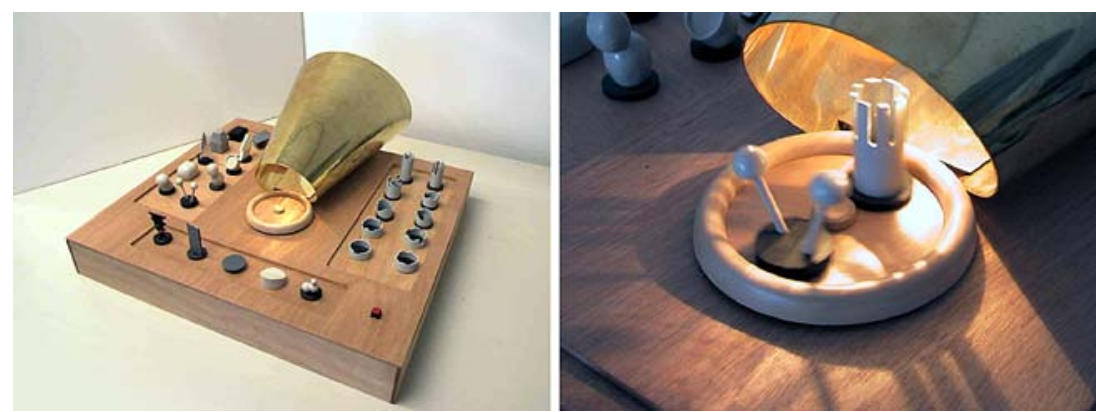

Fig. 2 Two pictures of Moto, the musical device designed from the direct approach, incorporating emotional expression of actions
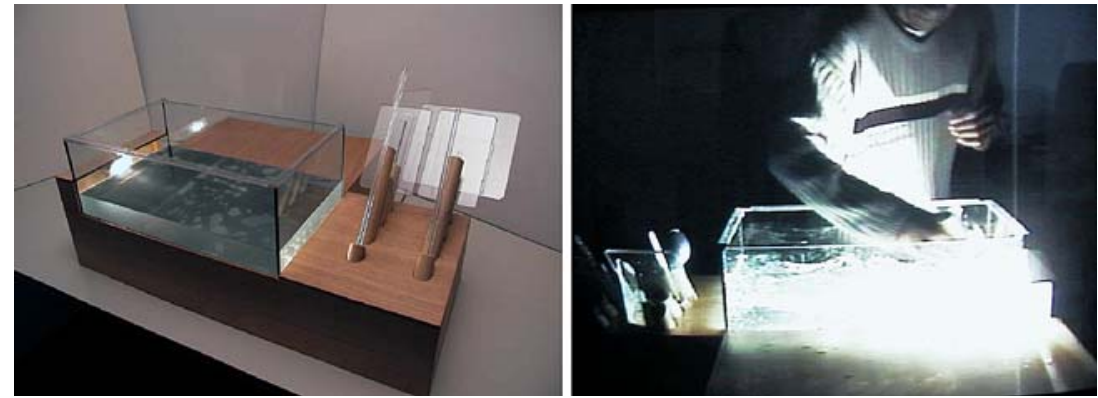

the resulting musical expression. The tools have similar handles, but create a different feel when moved through the water. The shape and materials of the blade vary per tool, which influences the amount of water it displaces, how it reacts to moving water and how much it is subject to upward pressure. Every tool has its own characteristic behaviour and feel, which allows a person to express a range of emotions. In contrast to Poco, with which musical expressions are made bit by bit, Moto enables a person to create an overall expression 'in one go': rhythm, chords and a sample are influenced simultaneously. Movies demonstrating Poco's and Moto's interaction are available on the Internet at http://www.philipross.nl.

\subsubsection{Evaluation}

We conducted an experiment with Coppia Espressiva to gain insight in the interaction experience of people in terms of engagement and the quality of the expressions they made on both devices. Eight participants were put in a variety of moods by means of a Mood Induction Procedure using film clips [9]. The participants were asked to express each mood by making music clips on both instruments. Interacting with Moto was perceived as more complex than interacting with Poco, all participants agreed. A common experience of the participants was that Moto seemed to be able to make more diverse and subtly varying music clips, with sheer endless possibilities. Moto sometimes gave musical feedback that did not match the participants' first expectations, which gave the interaction an explorative character. This divided the participants in terms of their appreciation of interacting with Moto. One group of participants indicated that their feeling of control over the Moto device was diminished below an acceptable level. This hampered their self-expression, which they experienced as a downside of the device. They preferred Poco and created their best musical expressions on Poco. The other participants however accepted Moto's complexity and demand for exploration. They indicated to be more emotionally involved when using Moto than when using Poco, which points towards meaningful engagement and enchantment. From this group, the remark came that interacting with Moto felt like really making music, while interacting with Poco felt like selecting music. This group made their best musical expressions on Moto.

Related to the sensibilities of design for enchantment, we can say that one group of participants appreciated paradox, openness and ambiguity of Moto (sensibility 4 and 5) and the direct nature of interaction gave them a stronger sense of being-in-play (sensibility 3). But the other group had quite a different preference, that of clarity and ease of use of Poco. This group enjoyed interacting with Poco's objects and actually had a negative, detached passive experience with Moto. We could say both products enchanted different people differently. This leads us to the conclusion that considering the person and choosing the design approach to fit this person is essential when designing for an enchanting interaction experience. The question remains how to do this. Our next case study links ethics to aesthetics of interaction as a way to incorporate people's desires, feelings and anxieties in interaction experience design. 


\subsection{Workshop Ethics and Aesthetics in Interaction}

In our design for meaningful mediation research, we aim to design interactive products that could invite a person to engage in intrinsically valuable activities. A person's notion of what is valuable has an ethical dimension: the question what is valuable in life entails a question about what is good in life. Therefore designing for meaningful mediation essentially incorporates ethics. In the workshop 'Ethics and Aesthetics in Interaction' we explored how to incorporate ethics in product design, focusing on mediation by interactive products, and explored how it could influence the resulting mediation.

\subsubsection{Points of departure}

2.2.1.1 Ethics in design Incorporating ethics in design is not new. Throughout the history of industrial design there have been relations between designed objects and ethical beliefs. Avant Garde designers, like the Dutch designers of "de Stijl'" in the 1920s, identified a problem with society, envisioned a utopia and tried to materialise it through design [10]. "De Stijl"' was a modernist movement, which means that they shared the belief that the social world could be changed through changing the material world: changing the built environment would change people.

Also today some designers have explicit ambitions to change people, but not all designers share this ambition. Society educates designers, who in most cases function within the given ethical framework of that society. For example, nowadays consumer products are commonly targeted at groups of people with their own socio-cultural identity, not primarily to change these people-although the question remains whether this will not happen anyway-but rather to satisfy a demand for products that help express these identities. Mobile phone ring tones are currently offered in large varieties. Teenagers use these ring tones to express a certain lifestyle or to demonstrate how 'cool' they are. When designing for socio-cultural identities, through for example "lifestyle"' analysis, the ethical beliefs that are part of these identities are, at least implicitly, incorporated in design.

\subsubsection{Incorporating ethics through aesthetics Both the} Avant Garde modernist designers and the mainstream designers mentioned in the previous use the expressive power of aesthetics as means to incorporate ethics in design. "De Stijl'”-designer Gerrit Rietveld used de Stijl's "universal", aesthetics, which entailed strict geometric shapes and primary colours in his famous Rietveld chair. Offering a cheap functional chair to the masses alone was only part of his intentions. An essential part of it was emancipating the people by allowing them to share in the universal aesthetics it embodied.

Aesthetics of form and materials are still a dominant means for designers to make products expressive. This form of aesthetics is related to McCarthy et al.'s first sensibility 'the sensuousness of each particular thing'. The increasing interactivity in products, enabled by digital technology, brings along a new, but not obvious design subject: the aesthetics of interaction [11]. Aesthetics of interaction is in our view what sensibility 3, 4 and 5 relate to, alongside sensibility 1 . Aesthetics of interaction is connected to experience of interaction with products in context. It is not confined to properties of an isolated product. Although a designer cannot design people's interactions with a product, he or she has the possibility to design a product to invite or entice people to interact with a product in a certain way. For example, a luxurious fountain pen with its delicate gold plated tip and balanced grip invites elegant writing, while a cheap Bic pen seems to invite fast scribbles. It is of course possible to write neatly with both pens, but the design of the fountain pen more likely results in people writing elegantly.

So different designs are prone to evoke interaction with different aesthetics. In the workshop "Ethics and Aesthetics in Interaction', we focus on design for aesthetics of interaction as a means to explore how to incorporate ethics in design for meaningful mediation. And related to design for enchantment, reflecting on this exploration will give insight about how 'aesthetics of interaction sensibilities', like sensibilities 3,4 and 5, could help achieve a desirable interaction experience for different people.

\subsubsection{Workshop set-up}

In the workshop three groups of designer/researchers each designed a set of two products. The assignment for each group was to design two functionally similar products, while incorporating a contrasting ethical system in each design. By comparing the two designs, we intended to learn how ethics influence the aesthetics of interaction and the resulting mediation in terms of engagement.

The one-day workshop was conducted at the department of Industrial Design at the Technische Universiteit Eindhoven in the Netherlands. Nine designer/researchers from industry and academics participated.

Five ethical systems were selected in cooperation with Dr. Jan Vorstenbosch, philosopher at the University of Utrecht, specialised in applied ethics and phenomenology of consumer product use. We selected ethical systems that could be linked to specific aesthetics in the arts, architecture or design and composed a set that was as diverse as possible. This set consisted of Confucianism, Kant's Rationalism, Vitalism, Romanticism and Nietzschian 
ethics. These ethical systems were made available to the workshop participants in multiple ways. Short text descriptions of the ethical systems were available, accompanied by related works of art, including poetry, music and video material to provide additional inspiration for design. The workshop space was divided in zones, in which the different systems could be absorbed in various ways (Fig. 3)

Four design assignments were composed. Each assignment combined one specific product functionality with two contrasting ethical systems to be incorporated in the designs. These functionalities included meal preparation, electronic payment, candy vending and slaughter and destruction of livestock. The intention was to create a diverse set of assignments regarding ethical implications-destruction of livestock seems to have more ethical impact than vending candy - to see how ethical impact of product functionality influences design for meaningful engagement. In this paper we treat only the candy vending machines, designed from Kantian rationalism and Romanticism.

\subsubsection{Candy vending machines: Kant versus Romanticism}

What would a Kantian candy vending machine look like, how would it mediate buying candy and how would it differ from a Romantic machine? How could both machines evoke meaningful mediation? What would the interaction experience be for a Romantic and Kantian person on these machines?

The workshop day started with an explanation and illustration of the ethical systems. After absorbing these systems, the participants designed the two devices starting from the intended aesthetics of interaction. The participants had approximately five hours to design and prototype their products. An 'acting out' design technique was used [12], which involves acting out the intended interaction of people and products in short scenarios. Subsequently, two physical products were designed to elicit the aesthetic interaction envisioned in the acting out scenarios. Functionality was simulated.

Before elaborating on the designs, we briefly treat the two relevant ethical systems. It goes beyond the scope of this paper to give a complete account of these systems, so we will limit the descriptions to a short impression. In Kant's rational ethics universal reason dictates moral rules of a formal character. We can reason about what is good and what is not, and once we know, we are obliged to act by it. In the workshop we used works of "de Stijl", painter Piet Mondriaan that share an aesthetic inspired by reason. The Romantics turn away from these rationalistic ideas. Instead of searching for a static universal truth, they are interested in the dynamic, non-rational forces on individuals and the world. The Romantics in general replace utilitarian for aesthetic values. What is beautiful is good. During the workshop, pictures of Rodin artworks and music by Liszt provided inspiration for design from Romantic aesthetics.

Figure 4 shows the physical mock-ups of the final 'Kantian' and 'Romantic' candy vending machines. From first inspection of Fig. 4 we can see that the physical designs differ noticeably, which points towards the difference in interactions the machines elicit. Before evaluating the devices, we first describe the intended interactions with the two devices the designers presented at the end of the workshop.

The 'Kantian' machine presents itself through a split panel with buttons and sliders (Fig. 4). On the left side of
Fig. 3 The workshop space featured areas devoted to a specific ethical system. The left picture shows the Romantic zone, which included pictures of Rodin artworks, a text description hanging from the ceiling and music by Liszt playing in the background. On the right a picture of an introduction to calligraphy that enriched understanding of Confucianist ethics
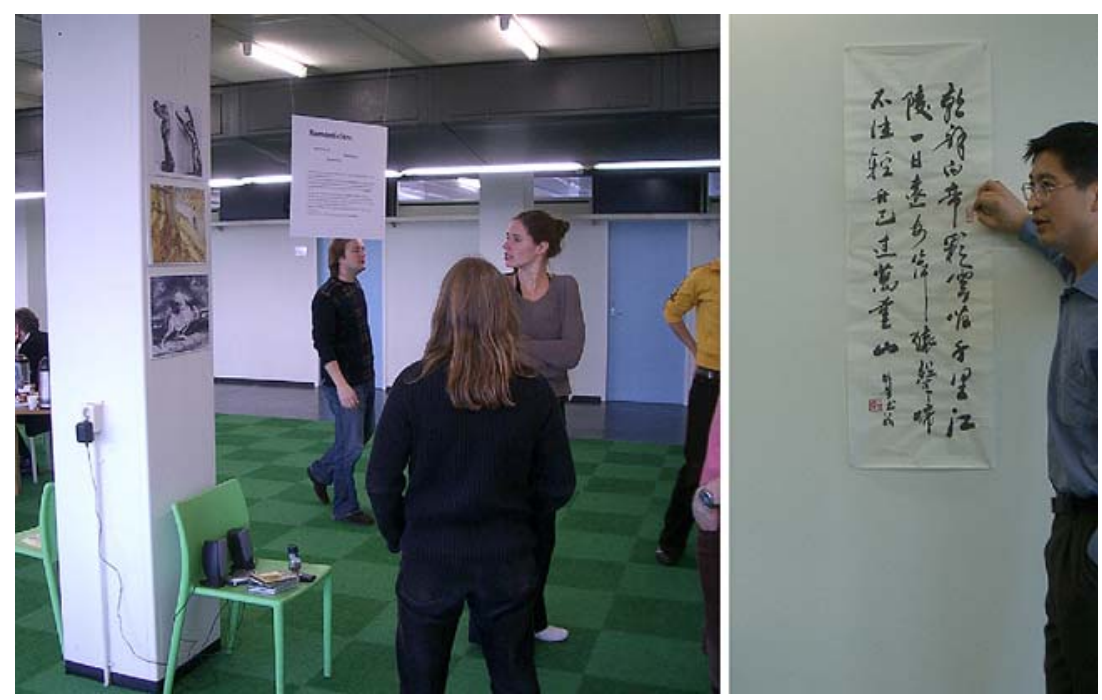
Fig. 4 The candy vending machines' physical appearances. Left picture: front panel of the Kantian machine mock-up. Right picture: the 'Romantic' machine
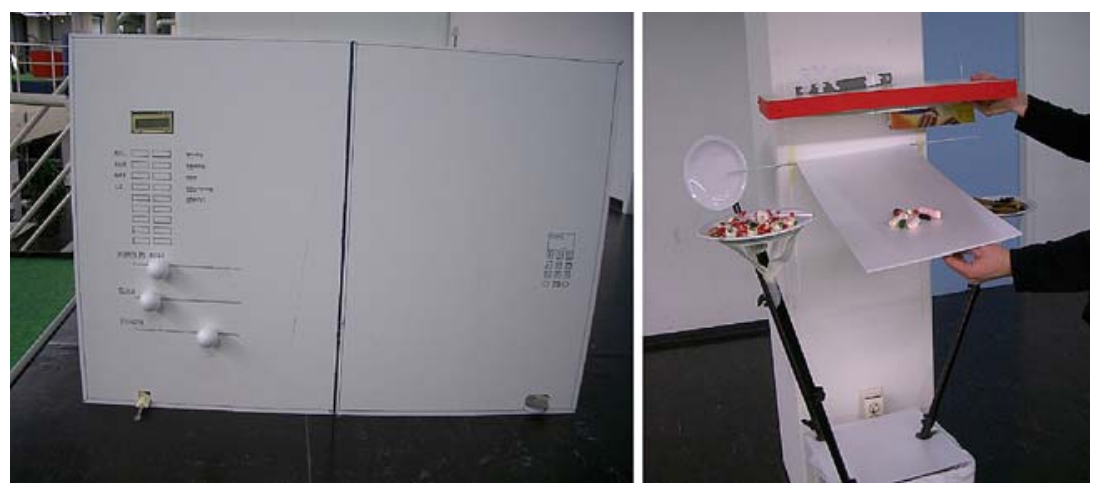

the panel, a person 'constitutes' candy by setting parameters like for example the amount of protein, carbon and fat (Fig. 5a). After adjusting the parameters, the machine advises a person to proceed or not, depending on his or her fat index (Fig. 5b). After weighing the advice, the person proceeds to the right side of the panel. The machine asks for a credit card and determines whether the buyer's financial situation allows the purchase. If so, the machine deposits a round piece of candy with the requested constitution in the slot on the bottom right (Fig. 5c, d)

The salient link to Kantian rationalist ethics in this design is the emphasis on reason throughout the process of buying candy. Abstractions are used to constitute a piece of candy, which is physically hidden behind these abstractions until the last moment. Kant's idea of duty to follow reason is implemented in the strict phased interaction that the machine imposes on a person and its prescriptive reminders of the candy buyer's fat index. The machine's interface resembles the interface of a traditional candy machine in the sense that it mainly consists of coded buttons.

The 'Romantic' machine physically presents the candy to the buyer, which allows this person to indulge in the sweet aromas and feel the lust for candy. Candy is selected by taking it from one of the presentation plates (Fig. 6a) and dropping it on a horizontal tray (Fig. 6b). When the buyer is satisfied with his selection of candy, he throws his money onto the money tray (Fig. 6c). Just after the machine sweeps the money in its container, the candy tray suddenly flaps down, overwhelming the customer with candy literally falling into his lap.

With hindsight, one could argue that salient aspects of this device are more hedonistic and sensuous than romantic. A Romantic device would involve 'higher' emotions like nostalgia or hope, while this device evokes more 'earthy' craving, like the lust for candy evoked by the presentation plates filled with candy. But there are elements in the design that are arguably romantic. The freedom of selecting candy in one's own spontaneous way resonates with Romantic value of individual freedom. The climax of releasing the candy, which gives this machine's interaction a dynamic character, is directly related to the Romantic love for dynamics and drama.

\subsubsection{Evaluating the workshop}

It should be clear that the candy vending machines discussed here are research prototypes that are not fully designed functionally. The value of these prototypes lies in what they can teach us through the particular ways they mediate buying candy, inspired by different ethics.

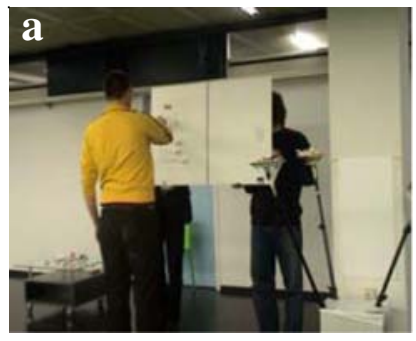

setting parameters

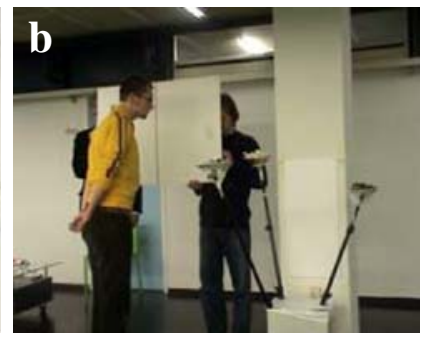

"Are you sure? Your

fat index is already above 17."

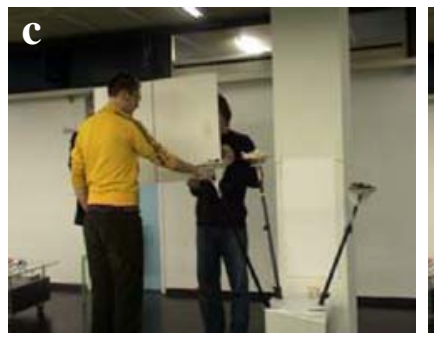

picking up the candy

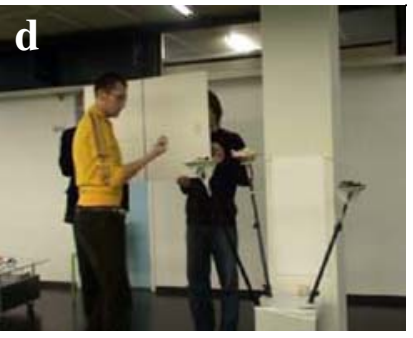

done.

Fig. 5 The acted out interaction with the Kantian vending machine 


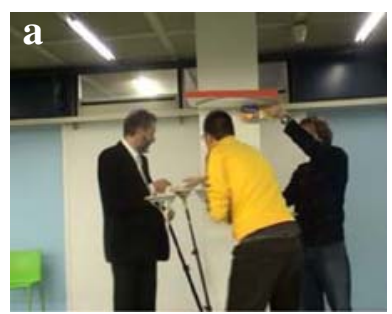

selecting candy physically...

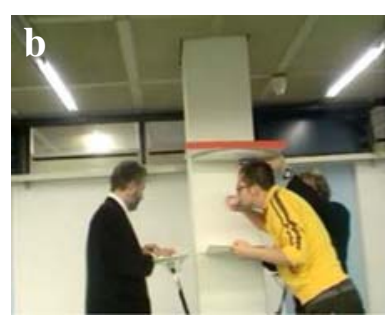

...even smelling it.

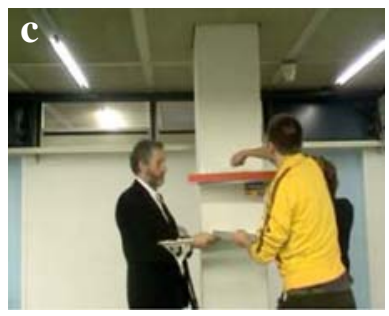

paying

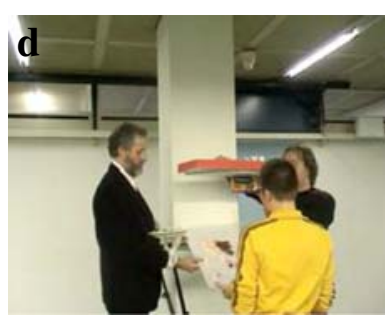

receiving the candy

Fig. 6 The acted out interaction with the 'Romantic' vending machine

Looking back on the workshop, we see that the designers succeeded in creating products with the same functionality while incorporating different aesthetics of interaction. The ethical systems actually inspired the designers and gave direction to their designs, resulting in innovative designs. Ethics influenced the designs on aesthetical aspects as varied as interaction dynamics, amount of control (sensibility 3: sense of being-in-play), physical appearance (sensibility 1: sensuousness) and behaviour (sensibility 5: transformational character). This makes ethics a useful input for designing the various aspects of an interactive product coherently. If we use ethics as a way to regard 'the whole person' (sensibility 2), we see how this has implications for the desirability and execution of the other sensibilities that are related to aesthetics of interaction.

Comparing the two vending machine interactions, we argue that both devices are likely to appeal differently to people that have different ethical beliefs. We are speaking in caricatures now, but it seems plausible that a Romantic person, valuing freedom and drama, would find the strict, phased and passionless interaction the Kantian device asks unappealing. On the other hand, a strict rationalistic person might find the lustful grabbing of candy, which the 'Romantic' machine elicits, appalling and the releasing of the candy unnecessary and unhandy. A pure rationalist likely prefers the rational mediation of the Kantian machine, with its clarity and abstractions (certainly not sensibility 4 'paradox and openness' and sensibility 1 'sensuousness'), while a Romantic person would prefer the free and dramatic mediation of the 'Romantic' machine, reflecting a rich sensuousness (sensibility 1) and a strong sense of being-in-play (sensibility 3). The Romantic machine allows a Romantic person to do what he finds intrinsically valuable: be part of a beautiful, dynamic and dramatic interaction. In this sense, the 'Romantic' candy vending machine could evoke meaningful engagement for a Romantic person and potentially an enchanting experience. If a rationalist person finds use of reason the only meaningful way to be involved with the world, design for rationalist mediation of his actions like the Kantian machine does, would be a prerequisite for him to find the mediation itself meaningful. We end this reflection on the two machines with the remark that how an activity is mediated is one thing, what activity is mediated is another. One could ask the question whether a Kantian person would ever find meaningful engagement in the activity of buying candy, for example.

This reflection on the two vending machines shows how the techniques used in the current workshop could help evaluate interaction prototypes in an early stage in relation to the desires of the 'whole person' of sensibility 2 .

\subsection{Incorporating human values in interaction: a study} with intelligent interactive lamps

The workshop 'Ethics and Aesthetics in Interaction' taught us how incorporating ethics in the design of aesthetics of interaction influences a device's potential to evoke meaningful engagement. It demonstrated that the sensibility for the whole person has strong implications for the desirability and execution of the other sensibilities. But naturally there were issues concerning design for meaningful mediation that the workshop left open. The workshop incorporated ethical systems of famous philosophers, but not ethics of real people. Secondly, there was lack of real interaction: Both the people interacting and the machines were acted out by designers performing a fixed scenario. The main questions we wanted to address after the workshop were the following:

- How could we describe more nuanced differences in people's ethics?

- Can ethics be incorporated in real interaction with real people?

- What is the effect of this incorporation on the potential for meaningful engagement for real people?

We conducted a pilot study, called 'Incorporating $\mathrm{Hu}$ man Values in Interaction', as a first attempt to address these questions. We cooperated with designer and dancer Sietske Klooster in setting up the experiment. In short, we asked dancers, specialised in improvisational modern 
dance, to act out intelligent home lamps and develop strategies to incorporate ethics in aesthetics of interaction. Subsequently, we tested these strategies with people with different ethics. Before elaborating on the study, we discuss the theoretical framework we used to address the first question: how to describe the more nuanced differences in people's ethics.

\subsubsection{Human values and meaningful engagement}

We made a shift of framework concerning ethics from philosophy to human value theory from social psychology. Ethics and values are not entirely similar concepts; values do not constitute explicit moral principles, for example. But they are closely related to ethics in the sense that they provide motivations for moral choices and moral evaluation of actions. The shift from ethics to human values provided us with a means to operationalise ethics and measure ethics of people.

Social psychologist Shalom H. Schwartz provides a definition of human values describing five formal features the concept incorporates: 'Values are (1) concepts or beliefs, (2) they pertain to desirable end-states or behaviours, (3) transcend specific situations, (4) guide selection or evaluation of behaviour and events, and (5) are ordered by relative importance.' [13]. Schwartz identified and evaluated a comprehensive set of 56 values, which includes concepts like Social Power, Creativity and Pleasure, and discovered a universal structure that organises values in a two-dimensional plane. This structure of human values reveals how compatible or conflicting values are. For example, more conflict exists between Social Power and Helpful than between the more compatible values Humble and Helpful. Schwartz grouped the set of values into 10 motivationally distinct value types. See Fig. 7 for a graphical representation of the theoretical structure of hu- man values. Schwartz developed a survey and method to measure individual people's value priorities and summarise them using the 10 value types.

When we look at the definition of human values, we see they pertain to desirable end-states and behaviours. This is where human value theory meets designing for meaningful mediation. Pursuing a desirable end-state that corresponds with a value, should be intrinsically valuable for a person that gives high priority to this value. Devices that allow or invite us to pursue the desirable end-state and behaviours corresponding with the values we find important therefore potentially evoke meaningful engagement. In our study, we use human values as a means to systematically incorporate different ethics in our designs for meaningful mediation. Concurrently, we use human values as a means to describe ethics of individuals. Used this way, human value theory provides a common ground for viewing people (sensibility 2) and design for interaction.

We think the value framework could help placing enchantment as one interaction experience in context with other possible interaction experiences. Enchanting experiences as described by McCarthy et al. correspond with the values in the categories Hedonism and Self-Direction, with values like pleasure, exciting life, curious and creativity. The value structure points towards a range of other possible interaction experiences, e.g., the more function related experiences related to Achievement values.

\subsubsection{Intelligent lamps study set-up}

Two questions posed in the introduction of this paragraph remain: can ethics be incorporated in real interaction with real people? And: What is the effect of this incorporation on the potential for meaningful engagement for real people? To address these questions, we devised the intelligent lamps study. We first chose a research carrier, i.e., intel-
Fig. 7 The structure of human values, including the demarcation lines of the ten value types. Distance in the diagram indicates the amount of conflict between values. A set of eight out of 56 values, relevant to the study described in this part, is included on their position in the structure. (This diagram is an adaptation from Schwartz [13])

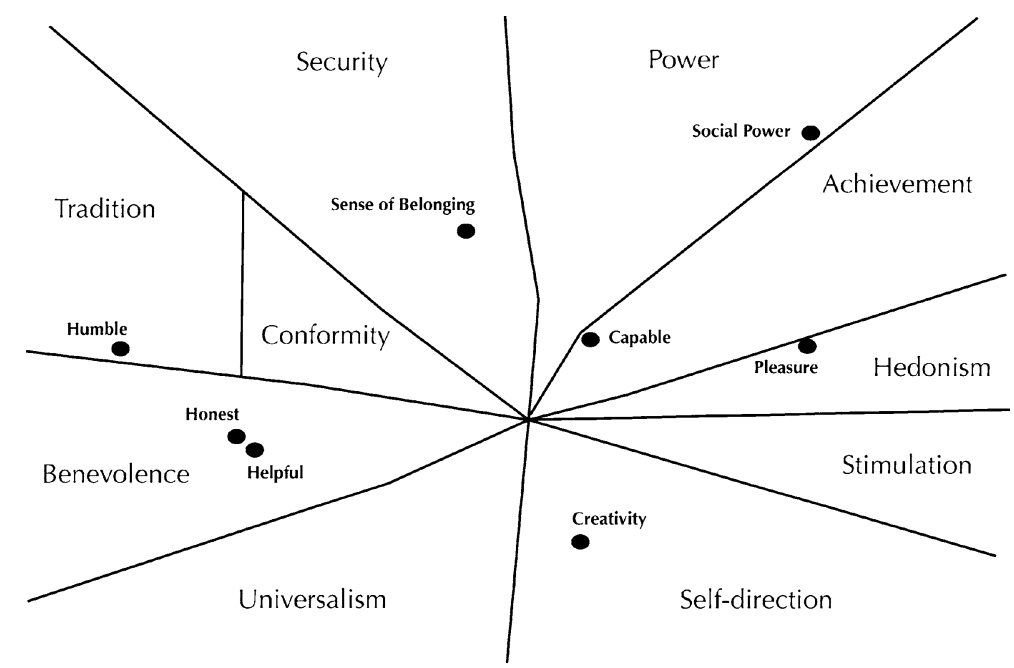


ligent home lighting. Light is an expressive medium and the home is where people have time for their personal lives. Furthermore, intelligence in home products and systems, or 'Ambient Intelligence' [4], is an upcoming technological development, with new and challenging implications for design.

At this stage, we did not have real intelligent lamps yet. Instead, we asked four professional improvisational dancers to act them out. We asked them to develop strategies to incorporate specific human values in interaction and act out the intelligent lamps in an experiment. Improvisational dancers, specialised in modern dance, are trained to use their body expressively. In their work practice, they need to be sensitive to other dancers, or even the audience, and adapt to them to be able to create a common expression on stage. Their bodily expressive and adaptation skills make these dancers pre-eminently suitable to act out the intelligent lamps in our pilot study. We designed light objects for the dancers, adjustable in brightness and easy to attach to the body, so that these lights could feel like part of their body (See Fig. 8).

The morning of the experiment day was reserved for the dancers to create and rehearse strategies to incorporate the specific values in interaction. We selected eight target values for the dancers to rehearse for. The eight values were chosen to constitute a diverse set that would span a large part of the value structure (literal descriptions from the Schwartz Value Survey):

- Social power (control over others, dominance)

- Humble (modest, self effacing)

- Helpful (working for the welfare of others)

- Creativity (uniqueness, imagination)

- Pleasure (gratification of desires)

- Honest (genuine, sincere)

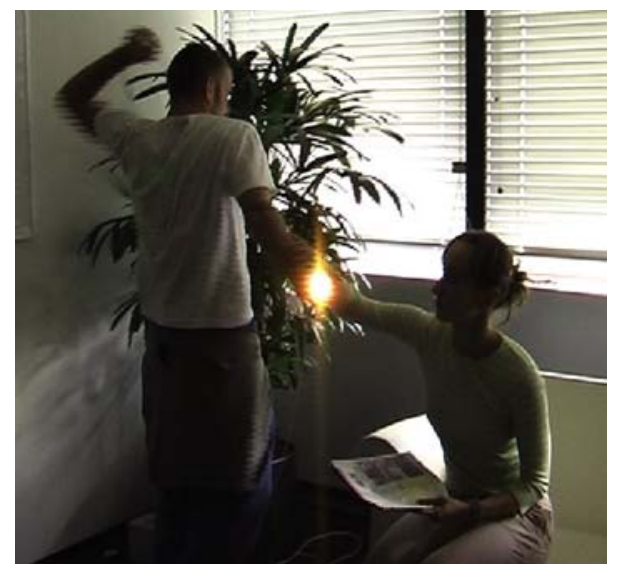

Fig. 8 On the left a dancer rehearses his strategy to incorporate the value Pleasure in aesthetics of interaction. The light object is attached to his right hand. He adjusts the light's brightness using his thumb, which does not interfere with the expression of the rest of his body
- Sense of belonging (feeling that others care about me)

- Capable (competent, effective, efficient)

Creativity and Pleasure seemed most related to design for enchantment. In the experiment, each one of the four dancers acted out two different intelligent lamps, which made a total of eight values. The dancers were placed in four different rooms that contained furniture and plants to create a living room like atmosphere (See Fig. 8).

2.3.2.1 Participants In the afternoon, eight participants were asked to interact with the 'lamps', acted out by dancers. We aimed to gather a group of participants with different value priorities. More specifically, we aimed to constitute a group that included four kinds of people, with the highest priorities each in one of the four quadrants of the value structure. We used the Schwartz Value Survey to select the eight final participants from a larger group of people. The final group consisted of 5 males and 3 females aged between 25 and 65. Professions were manager in an industrial company, sculptor, sustainable development engineer, housewife and student of physical education, mechanical engineering and physics.

2.3.2.2 Procedure The participants first received a tryout workshop in which they learned how to interact with a dancer, using their own and the dancer's body, and not using speech. When every participant was accustomed to interact by means of his body with an acted out lamp, the actual experiment began. Each participant was asked to interact with eight lamps in a specified order. The participants were asked to imagine they were in a typical home scenario: They would just have had dinner at the kitchen table and decided to move to the living room, where it had

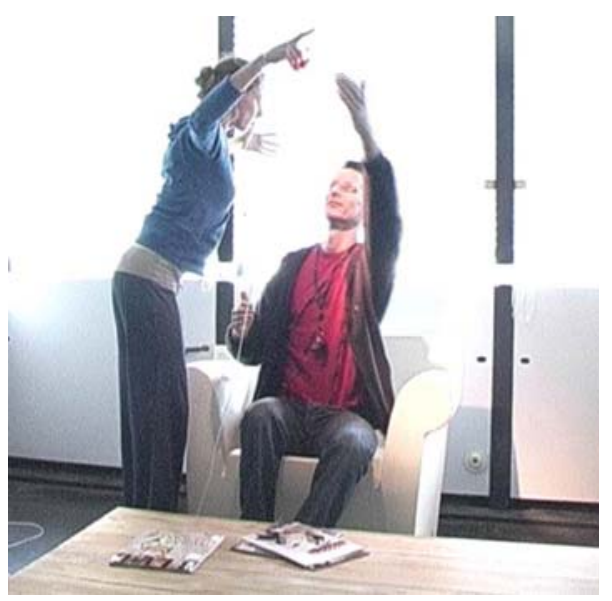

Fig. 9 A scene from the experiment. The dancer on the left tries to elicit the value 'humble' in interaction 
become dark during dinner. In this context, they were asked to use the lamp in the room (the dancer) to create the right lighting atmosphere for reading a magazine on the couch. See Fig. 9 for a scene of the experiment. In total each 'lamp', which targeted a specific value, elicited eight interactions.

After each interaction, a participant was asked to fill out an 'interaction evaluation form'. On this form, the participants indicated how they felt during interaction using SAM scales [14] and to what extent the participants felt like they were behaving according to the eight values that were targeted by the 'intelligent lamps'.

\subsubsection{Dancer strategies}

As an illustration of how the dancers incorporated different human values in interaction, we describe the strategies the dancers used. We limit the treatment to the values Social Power, Creative and Helpful in interaction, because these three 'lamps' succeeded best in their intentions according to the scores on the interaction evaluation forms.

The dancers used strategies they created and rehearsed before the participants came in. These strategies consisted of their interaction rationale, an abstract description of their intended interaction, combined with the way they would deploy their body in interaction. We first describe three of these strategies using scenes from the experiment. Dancer Houkje van Hoek received the assignment to incorporate the value Creative in interaction with the participants. Her main strategy was to offer a playful puzzle like interaction, which would change every now and then to keep the puzzling aspect in the interaction. Figure 10 illustrates her strategy.

Figure 11 shows scenes from the experiment in which dancer Rainer Muentinga, who tried to incorporate Social Power in interaction with the participants. His general strategy was to make another person feel powerful by taking on a humble attitude, like a servant. The 'lamp' Rainer tries to continuously anticipate the actions of the participant. During the entire interaction, the light takes on a slightly bent posture, to physically remain subservient.

The third value we treat is Helpful, which has a large distance to Social Power on the value structure. Figure 12 shows how dancer Rainer Meuntinga incorporated this value in interaction.

During the experiment, the dancers used their strategies as a blueprint for their behaviour and reactions to actions of the participants. With the goal of the interactions in mind, they improvised to adjust to the different actions of the different people. The dancers called this 'structured improvisation'. For example, when Houkje van Hoek tried to incorporate the value Creative in interaction, she would adjust the amount and timing of the hints she gave to the progress of the puzzling participants and their patience. The dancers indicated that improvisation in reaction to the different people was essential for reaching their goal.

\subsubsection{Evaluating the study}

Before continuing with the evaluation, we remark that these lamps are not intended as first steps to commercial

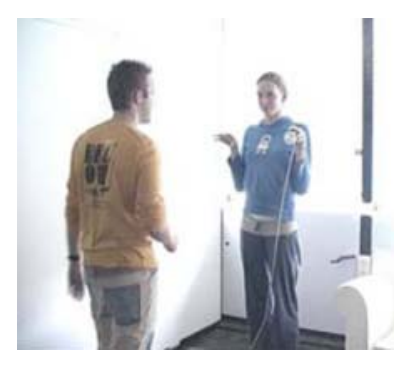

1. The 'lamp' awaits the participant.

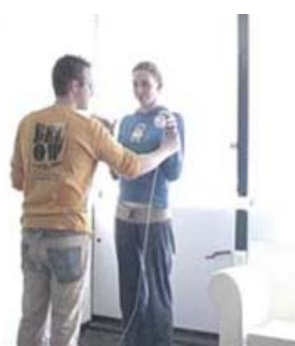

2. The participant tries to adjust the 'lamp' by pulling on the left arm, which does not work. The 'lamp' gives a playful hint by wiggling the fingers of her right hand.

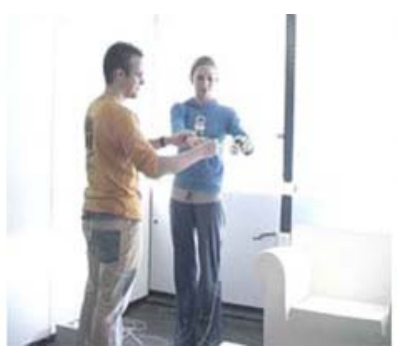

3. The 'lamp' moves when the right arm is manipulated. It mirrors every move made on the right arm with the left arm.

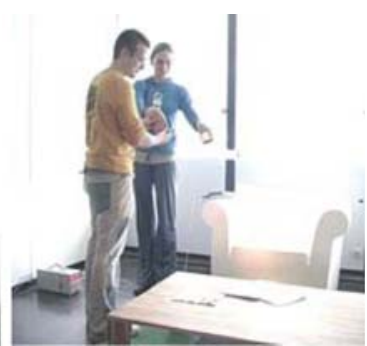

4. After puzzling for a while, the participant finds how to bend the lamp's hand to switch the light on. The lamp is now set up for reading.

Fig. 10 The 'lamp' on the right tries to evoke creativity in interaction by offering a playful puzzle-like interaction 
Fig. 11 Scenes from the experiment show how the 'lamp', acted out by a dancer in black, tries to incorporate the value Social Power in interaction for the participant
Fig. 12 Scenes of the experiment in which the dancer tried to incorporate the value Helpful in interaction

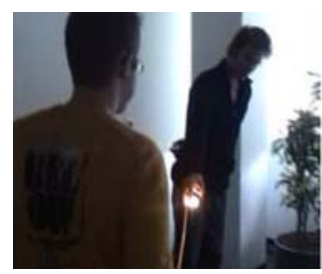

1. The lamp lights the ground before the steps of the participant, anticipating where he is going.

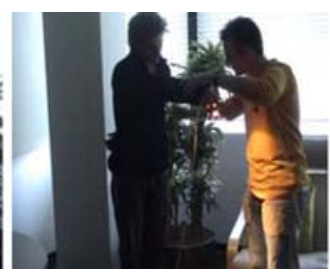

2. The lamp's posture is slightly bent down. It allows easy adjusting.

highlights the

magazines when the

participant reaches out

to select what to read.

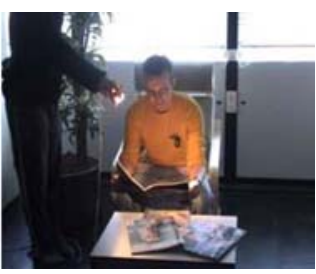

4. The lamp follows the gaze of the participant with its spotlight.

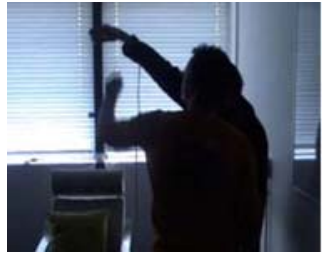

1. The participant reaches for the light to try to switch it on.

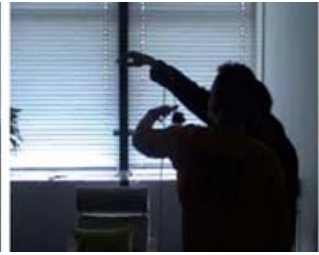

2. The 'lamp' drops its light object, which now hangs loosely from its arm.

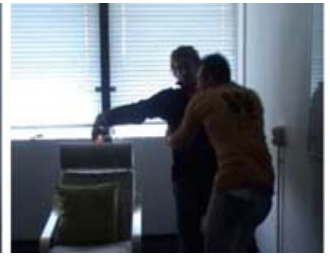

3. When the participant tries to reinstall the light object, the lamp itself becomes unstable. The participant helps keep it standing.

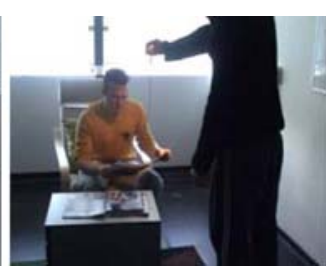

4. The lamp finally stands after a series of near breakdowns. products. One could ask oneself how eager someone would be to buy a lamp that continuously needs help. Although we do not exclude this possibility, this question is not relevant at this point.

When we look at whether people felt like they were acting according to the values, we can tentatively conclude that the three lamps treated in this paper succeeded in their goal: the values that were targeted were scored high in the evaluation forms relative to most other values. Compatible values, values that are positioned closely in the value structure, received high mean scores as well. In one way this is disappointing, since it seems hard to isolate a particular value. On the other hand, it seems in line with the value theory that states that values close to each other have similar implications.

The lamp targeting Creativity is closest to targeting an enchanting experience. We see that in particular sensibility 3 'a sense of being-in-play', 4 'paradox, openness and ambiguity' and sensibility 5 'the transformational character of experience' all apply to the structured improvisation of this lamp. Furthermore, these sensibilities apply better to the Creativity lamp than the Helpful and Social Power lamps, which target other interaction experiences than enchantment. So this design case study points towards the credibility of these sensibilities in design for enchantment.

The dancer strategies give useful information about the 'how to' question we posed in the introduction of this experiment. The dancers formulated strategies that constituted a blueprint for the way they would behave and react to people. Their improvising skills helped them adjust to the different actions of different people, while keeping their goal of interacting in mind. These 'structured improvisations' give valuable input to the design process. The dancers' rationale could provide input for the design of the behaviour of a lamp and the dancers' physical strategies could be translated to properties and movements of the physical device. For example, the way the dancer, targeting Social Power, followed the gaze of the participant with the light could be implemented in a lamp that can direct its light and has the sensors and intelligence to do so. The slightly bent posture of the dancer that was always directed at the participant, expressing his humbleness can be 
translated into a general curve in the shape of the lamp. If it is equipped with sensors to detect proximity and movement around it, it could rotate around its vertical axis to direct itself to the person interacting.

Essential questions still remain. For example, how the ethics of individual people influenced the potential to evoke meaningful engagement by the different lamps. And to rule out the effect of people interacting with people, the experiment should be repeated with functional prototypes instead of lamps acted out by people.

\section{Concluding remarks}

We critically viewed and expanded on design for enchantment as described by McCarthy et al., based on our experiences from our own research into design for meaningful mediation. Conducting the Coppia Espressiva case study taught us that considering the whole person, as described in sensibility 2 , influences the desirability of the other four sensibilities and their realisation. The workshop 'Ethics and Aesthetics in Interaction' proposes incorporating ethics in aesthetics of interaction as a means to couple the 'whole person' to design for interaction experience. It also shows possible techniques to do this. In the intelligent lamps study, we positioned enchantment in a framework implying other possible interaction experiences, i.e., the structure of human values. The study results allow a tentative conclusion that it is possible to target specific interaction experiences, related to a value, through specific 'structured improvisations'. Analysing the design strategies of the lamps indicates the sensibilities 3,4 , and 5 are indeed relevant to design for enchantment. The techniques used in the study could be of use in design for enchantment in the context of intelligent products.

We think the design activity in the three case studies was essential in gaining the insights about design for enchantment described in this paper. We learn about design by doing it and reflecting on it. Our main conclusion related to McCarthy et al.'s work on enchantment is that considering the 'person' sensibility (sensibility 2) should come first to determine which sensibilities to take into account and how to realise them in design. Using the sensibilities this way will provide valuable inspiration and guidance in design for deep, enchanting interaction experiences.

Acknowledgements We thank Peter-Paul Verbeek for his useful comments on this paper, Sietske Klooster for her help in setting up the empirical study, and Professor S.H. Schwartz for providing the Schwartz Value Surveys along with instructions on use. We thank Jan Vorstenbosch for his contributions to the workshop 'Ethics and Aesthetics in Interaction' and the dancers Angelina Deck, Rainer
Meuntinga, Houkje van Hoek and Werner Nigg for their skills and enthusiasm in our experiment. Furthermore, we thank the participants of the experiment and Joep Frens, Kevin van der Steen, Geert van den Boomen and Loy Rovers for the essential technical assistance and general help before and during the experiment. The workshop 'Ethics and Aesthetics in Interaction' was supported by the J.F. Schouten Research School.

\section{References}

1. Bennet J (2001) The enchantment of modern life: attachments, crossings and ethics. Princeton University Press, Princeton

2. McCarthy J, Wright P, Wallace J, Dearden A (2007) The experience of enchantment in human-computer interaction. Personal and ubiquitous computing. Available at Online First: DOI $10.1007 / \mathrm{s} 00779-005-0055-2$ (in press)

3. Verbeek PP (2005) What things do-philosophical reflections on technology, agency, and design. Penn State University Press, Penn state, pp 173-195

4. Vorstenbosch JMG (2000) 12 Huishoudelijke apparaten. Filosofische bespiegelingen. Nieuwezijds, Amsterdam, pp 40-47

5. Aarts E, Marzano S (2003) The new everyday, views on ambient intelligence. 010 Publishers, Rotterdam

6. Hummels CCM, Ross PR, Overbeeke CJ (2003) In search of resonant human computer interaction: building and testing aesthetic installations. In: Rauterberg M, Menozzi M, Wesson J (eds) Proceedings of interact. IOS Press, Amsterdam, pp 399406

7. Djajadiningrat JP, Wensveen SAG, Frens JW, Overbeeke CJ (2004). Tangible products: Redressing the balance between appearance and action. Spec Issue Tangible Interact J Pers Ubiquit Comput 8:294-309

8. Gibson JJ (1986) The ecological approach to visual perception. Erlbaum, Hillsdale

9. Wensveen SAG, Overbeeke CJ, Djajadiningrat JP (2002) Push me, shove me and I know how you feel. Recognising mood from emotionally rich interaction. In: Proceedings of the DIS2002. ACM Press, New York, pp 335-340

10. Bürdeck BE (1996) Design-Geschiedenis, theorie en praktijk van de produktontwikkeling. Ten Hagen \& Stam B.V., Den Haag, pp 250-264. Dutch translation of Bürdeck BE (1991) Design-Geschichte, Theorie und Praxis der Produktgestaltung (1991) DuMont Buchverlag GmbH und Co. Kommanditgesellschaft, Cologne, Germany

11. Petersen MG, Iversen OS, Krogh PG, Ludvigsen M (2004) Aesthetic interaction: a pragmatist's aesthetics of interactive systems. In: Proceedings of conference on designing interactive systems DIS 2004, pp 269-276

12. Buur J, Jensen MV, Djajadiningrat JP (2004) Hands-only scenarios and video action walls-novel methods for tangible user interaction design. In: Benyon D, Moody P, Gruen D, McAraMcWilliam I (eds) Proceedings of the conference on designing interactive systems: processes, practices, methods, and techniques. ACM Press, pp 185-192

13. Schwartz SH (1992) Universals in the content and structure of values: theoretical advances and empirical tests in 20 countries. Adv Exp Soc Psychol 25:1-65

14. Lang PJ (1985) The cognitive psycho-physiology of emotion: anxiety and the anxiety disorders. Lawrence Erlbaum, Hillsdale 